\title{
RADIOGRAFÍA DE LOS COMPORTAMIENTOS DEL CLERO EN LA COMARCA DEL RIBEIRO
}

\author{
Por \\ ENRIQUE BANDE RODRÍGUEZ
}

La vida del clero se mueve en dos ámbitos bien definidos y totalmente distintos: uno sagrado y otro profano, por ello tenemos que analizar los comportamientos del clero en el templo y fuera de él.

\section{1.- COMPORTAMIENTOS DEL CLERO EN EL TEMPLO}

Manda el visitador que el abad, su teniente y los demás eclesiásticos de esta feligresía de aquí en adelante en las ocasiones y tiempos que estuviesen dentro del templo para celebrar el santo sacrificio de la misa, honras fúnebres, asistencia a vísperas cantadas, vigilias de entierros, y otras funciones solemnes y públicas no tomen tabaco por la gran indecencia que de hacerlo se causa como ya se ha comprobado experimentado y así lo ejecuten y observen en dichas ocasiones y tiempos bajo pena de excomunión mayor y apercibimiento.A los cuales también les exorta a que no hablen en la iglesia bajo las mismas penas y censuras por ser notable indecencia y porque deben estar en el templo de Dios con todo silencio y devoción, siendo los eclesiásticos los primeros que deben observarlo para que a su imitación lo observen los seglares ${ }^{1}$. Los visitadores también les manda a los clérigos que no tomen

\footnotetext{
${ }^{1}$ VIEITE, San Adrián. Libro de fábrica y visitas 1708-1856. 22.18.9, fol. 18. BEIRO, San Pedro. Visitas 1591-1702. 22.4.7, fol. 74.

VILLAR DE CONDES, Sta. María. Libro de visitas 1670-1778. 22.19.7, fol. 26.

CARBALLEDA, San Miguel. Libro de fábrica y visitas 1636-1709. 22.5.8, fol. 68 .
}

"CUADERNOS DE ESTUDIOS GALLEGOS", Tomo XLVII, Fascículo 113, Santiago 2000. 
parva, refresco ni otra cosa alguna en la iglesia, la sacristía y su atrio con motivo de funciones ni por ningún otro pretexto para ello². Manda que los clérigos o abades no hablen ni conversen entre sí y menos con otras personas dentro de la iglesia y si lo contrario hicieren da comisión al abad para que pueda privarles del emolumento correspondiente por la función o funciones en que contravienieren dichos clérigos y si fuesen contumaces dará cuenta a S. Ilma. o a su provisor para que procedan contra ellos $^{3}$.

\section{2.- ASISTENCIA DE LOS CLÉRIGOS A FUNCIONES}

Los visitadores mandan que los sacerdotes ordenados in sacris y los de menores que fueren vecinos o residentes o asignados a esta parroquia $o$ feligresía asistan a las funciones que en ella se celebren en los dos primeros días de las cuatro pascuas del año, semana santa y demás fiestas solemnes de primera clase en las que se vistirán alternando entre sí los ordenados in sacris diáconos y subdiáconos en la misa mayor, empleándose los de menores en los oficios propios de su ministerio y los que sobraren oficiarán desde el coro en las cuales se emplee a los de menores en oficios propios de su ministerio ${ }^{4}$. Cuando hubiere funciones fuera de la feligresía y dentro de ella en el mismo día los residentes hijos y vecinos deben asistir y preferir las funciones que se hacen dentro de la feligresía por ser esta obligación y ser en ella preferidos a los de fuera y por la misma razón deben ser preferidos a las asistencias a esta parroquia. Encargamos que todos los clérigos de ella como se dispone en el Santo Concilio de Trento y en las sinodales de este obispado asistan a las tres rogativas de San Marcos y temporas y a la semana santa en su parroquia y a los que no lo ejecutaren por la primera vez se les multe en dos reales aplicados a la fábrica de la iglesia de suerte que la ausencia no sea maliciosa y por la tercera vez se dará parte para proceder contra ellos a mayores castigos, lo mismo asistirán cuando se hicieren rogativas públicas por las necesidades de la iglesia y salud de nuestros reyes y señores y por las necesidades

\footnotetext{
${ }^{2}$ VILLAR DE CONDES, Sta. María. Libro de visitas 1670-1778. 22.19.7, fol. 52v.

${ }^{3}$ REGODEIGÓN, San Cristobo. 3 Visitas 1744-1829. 37.6.8, fol. 2.

${ }^{4}$ REGODEIGÓN, San Cristobo. Visitas 1747-1829. 37.6.8., sin foliar.

VIEITE, San Adrián. 22.18.9., fol. 140.
}

"CUADERNOS DE ESTUdIOS GALLEGOS", Tomo XLVII, Fascículo 113, Santiago 2000. 
públicas. Los eclesiásticos somos los primeros que debemos acudir a ellas implorando de Dios la misericordia. Los jueves santos deben todos los eclesiásticos comulgar de manos del propio párroco sin decir misa ese día. Encargamos a todos los eclesiásticos lo ejecuten y cuando en los días festivos dijeren misa en alguna capilla, sin perjuicio del derecho parroquial no deben permitir asistir a ella los feligreses los cuales deben concuriri a la parroquia a oír la explicación del evangelio ${ }^{5}$.

\section{3.- TRAJE DE LOS CLÉRIGOS EN LAS FUNCIONES DE LA IGLESIA}

Manda el visitador que el abad no le de ornato para celebrar a clérigo no conocido sin licencia in escriptis de S. Ilma., ni tampoco al conocido que sea de esa parroquia viniendo a decirla sin sotana y con las polainas ${ }^{6}$. No admita a las funciones que se hicieren en la iglesia a sacerdote alguno que no cumpla con lo mandado en la circular de 14 de febrero de 1827. Manda que el abad no admita en su parroquia a clérigo alguno en las funciones ya sean solemnes o fúnebres sin que lleve puesta sotana entera, sobrepelliz, bonete y coronilla abierta sobre lo que carga la conciencia al referido abad que es o fuere haciéndole responsable de cualquier omisión en esta parte, preveniéndole no les dé en caso de que ocurran las providencias correspondientes ${ }^{7}$. Ningún sacerdote sea admitido a fiesta del Santísimo Sacramento y de Nuestra Señora ni a sus procesiones sin que vaya con sobrepelliz bajo la pena de excomunión mayor y apercibimiento ${ }^{8}$. No se dé ornato para celebrar misa a los clérigos sin licencia in escriptis de S. Ilma. Así mismo manda que dichos clérigos y abades no hablen ni conversen entre sí y menos con otras personas y a los que esto contravenieren S. Ilma. da comisión a dicho abad para que pueda privarles del emolumento correspondiente por la función el cual emolumento se ha de expender en utilidad de dicha parroquia y si fueren contumaces dará cuenta a S. Ilma. o al provisor ${ }^{9}$.

\footnotetext{
${ }^{5}$ VIEITE, San Adrián. 22.18.9, fol. 19v.

${ }^{6}$ VIEITE, San Adrián. 22.18.9, fol. 57.

${ }^{7}$ REGODEIGÓN, San Cristobo. 37.6.8, sin foliar.

${ }^{8}$ VILLAR DE CONDES, Santa María. 22.19.7, fol. 14v.

${ }^{9}$ VIEITE, San Adrián. 22.18.9, fol. 56.
} 
S. Ilma. está informado de que algunos sacerdotes andan por las aldeas sin cuello, que celebran el santo sacrificio de la misa y asisten a las funciones así en misas como en procesiones con sotanillas cortas que les llegan hasta la rodilla. Para evitarlo y para que todos asistan con la decencia de su estado, manda que ninguno de hoy en adelante celebre el santo sacrificio de la misa ni admita a función alguna sin que sea con sotana larga, sobrepelliz, cuello, alzacuello y bonete ${ }^{10}$. Siendo los primeros que lo deben ejecutar los abades para que a su imitación y ejemplo lo practiquen los demás y el dicho abad o cura no los admita a ningunas funciones sin que sea en la conformidad que va expresada. Habiendo llegado a nuestros oídos que en muchas parroquias de su obispado asisten los eclesiásticos a las funciones de ellas sin llevar el traje correspondiente a tan alto ministerio ordena que el abad que es o fuere de la parroquia no admita en lo sucesivo a las funciones que se hicieren en ella así fúnebres como festivas a ninguno que no cumpla con los autos de la visita ${ }^{11} \mathrm{y}$ con lo prevenido en la circular impresa el 14 de febrero de 1827, llevando además cuando asistan a aquellas sotana, sobrepelliz, bonete y coronilla abierta, sobre lo que carga la conciencia del abad ${ }^{12}$.

\section{4.- VESTIDO DE LOS CLÉRIGOS FUERA DE LA IGLESIA}

El visitador nos dice que está informado de que algunos sacerdotes fuera de la iglesia andan por las aldeas sin cuello y por ello le manda que en sus casas ni fuera de ellas traigan virretes o virretonas en la cabeza de ningún color pués más parecen ser seglares y militares que ministros de la iglesia y sólo les permite que traigan en dichos casos los tales virretes negros o blancos por el camino debajo del sombrero a causa del sudor y de no hacerlo así cumplir y efectuar el abad a sus sacerdotes será castigado y se procederá contra ellos a lo más que haya lugar ${ }^{13}$. Manda que ningún ordenado in sacris salga de su casa sin alzacuello y sombrero de teja ni use en

\footnotetext{
${ }^{10}$ VILLAR DE CONDES, Santa María. 22.19.7, fol. 24.

${ }^{11}$ VIEITE, San Adrián. 22.18.9, fol. 153.

${ }^{12}$ VIEITE, San Adrián. 22.18.9, fol. 155.

${ }^{13}$ VILLAR DE CONDES, Santa María. 22.19.7, fol. 24.

VIEITE, San Adrián. 22.18.9, fol. 15v.
}

"CUADERNOS DE ESTUDIOS GALLEGOS", Tomo XLVII, Fascículo 113, Santiago 2000. 
sus vestidos otros colores que los correspondientes a su estado, absteniéndose de usar de sombreros boleados o redondos observando lo prevenido en la circular de 20 de julio de 1813 así en este particular como en los demás que comprenden imitan el ejemplo de los eclesiásticos de la capital con los cuales procurarán conformarse en todo cuanto les sea posible ${ }^{14}$.

\section{5.- CONDUCTA CLERICAL FUERA DE LA IGLESIA}

Atendiendo S. Ilma. a que los que deben ascender al estado sacerdotal deben manifestar la pureza de las costumbres dando buenos ejemplos a todos especialmente a los vecinos de la iglesia donde residen con la frecuencia de los sacramentos con que se purifican para tan alta dignidad manda que todos los clérigos ordenados de menores y consignados comulguen a lo menos una vez en cada mes en su parroquia y los ordenados in sacris de epístola o de evangelio confiesen y comulguen cada 15 días y el abad o cura de esta feligresía cuando remita la certificación de haber cumplido con el precepto pascual certificará así mismo de los clérigos de su feligresía según su estado y órdenes si cumplen o no con este mandato para lo cual si no lo hiciesen no sean promovidos a otras órdenes y el abad lo cumpla con apercibimiento de que se procederá contra él a lo que haya lugar ${ }^{15}$.

\section{6.- ASISTENCIA DE SACERDOTES A FERIAS}

Manda que los clérigos no vayan a las ferias a comprar ni a vender por sí mismos ni que intervengan personalmente en compra ni venta alguna y cuando tuvieren que ejecutarlo lo hagan por medio de seculares en las referidas ferias y lo cumplan bajo pena de excomunión mayor late sentencie y le encarga al abad tenga todo celo y cuidado del cumplimiento de este mandato ${ }^{16}$.

\footnotetext{
${ }^{14}$ REGODEIGÓN, San Cristobo. 37.6.8, sin foliar.

${ }^{15}$ VIEITE, San Adrián. 22.18.9, fol. 28.

${ }^{16}$ REGODEIGÓN, San Cristobo. 37.6.8, sin foliar.
}

"CUADERNOS DE ESTUdios GALLEGOS", Tomo XLVII, Fascículo 113, Santiago 2000. 


\section{7.- EXORCISMOS HECHOS POR CLÉRIGOS}

Manda S. Ilma. que ningún clérigo de dicha parroquia y obispado haga exorcismos a persona alguna por ninguna causa ni motivo sin haber obtenido primero licencia in escriptis de S. Ilma. bajo pena de las dichas censuras y de la aplicación de los cánones en que incurran ${ }^{17}$. Manda que ningún sacerdote se propase a hacer exorcismos sin expresa licencia de $\mathrm{S}$. Ilma. y que lo cumpla inviolablemente con apercibimiento de que se procederá contra los inobedientes al severo castigo a que haya lugar y los párrocos celen sobre que así se observe dando cuenta en caso de contravención bajo pena de apercibimiento ${ }^{18}$.

\section{8.- COMIDAS DE SACERDOTES EN FIESTAS, COFRADÍASY FUNCIONES FÚNEBRES}

Manda S. Ilma. al dicho abad y a los mayordomos que tuviesen la festividad y las vísperas no den de comer a ningún género de personas, ni de almorzar en el día de la festividad por las muchas ofensas, disensiones, discordias y gastos que de hacerse se ocasionan y manda que el abad y los sacerdotes bajo multa de 4 ducados no asistan a dichas comidas y convites así de las vísperas como del día de la fiesta a almuerzos del día de la festividad y sólo se les permitía a dicho abad y eclesiásticos un desayuno leve en el atrio de la iglesia en el día de la festividad y en las vísperas un refresco percibiendo en dinero de los mayordomos la limosna que les corresponde. De las personas que contravinieren este mandato el abad dará cuenta a S. Ilma. para mandarle compeler al cumplimiento y en lo tocante a otras comidas que se ofrezcan así de entierros como en domingos de ofertorio, bodas y bautizos los eclesiásticos de esta dicha feligresía no concurrirán a dichas comidas y convites ${ }^{19}$. De su contravención el abad y cura dará cuenta a S. Ilma. quien así mismo manda que el día de la festividad haga que se diga y celebre misa a las once de dicho día y a dicha hora concurran los mayordomos y los feligreses de esta feligresía para oír di-

\footnotetext{
${ }^{17}$ VIEITE, San Adrián. 22.18.9, fol. 36v.

${ }^{18}$ REGODEIGÓN, San Cristobo. 37.6.8, sin foliar.

${ }^{19}$ VIEITE, San Adrián. 22.19.9, fol. 25.
}

"CUADERNOS DE ESTUDIOS GALLEGOS", Tomo XLVII, Fascículo 113, Santiago 2000. 
cha misa con apercibimiento de lo que haya lugar ${ }^{20}$. El visitador renueva los mandatos que previenen a todos los eclesiásticos no vayan a comer a las casas de los mayordomos de cofradías y devociones de los santos en el día de la festividad por los excesos y detrimentos que de ello se siguen y que lo cumpla como nuevamente lo mandamos celar al abad o cura en la parte que le corresponda y también para que no se origine gasto alguno para dicho fin aunque los mayordomos lo intenten voluntariamente. Estos sólo pueden socorrer a dichos eclesiásticos con una leve parva y desayuno fuera del atrio además de las derechuras y uno y otro se observe como así está mandado con apercibimiento ${ }^{21}$. Manda que los sacerdotes de esta feligresía de aquí en adelante ni otra persona alguna tomen parva, refresco ni otra cosa en la iglesia, sacristía y atrio con motivo de funciones ni con otro pretexto ${ }^{22}$. Manda S. Ilma. que de hoy en adelante ningún feligrés con ocasión de que se le muera una persona no dé de comer como está mandado por las visitas que se hallan en el libro viejo a los parientes y más personas que van a ofrecer ofrendas por cuanto se siguen muchos inconvenientes y excesivos gastos en perjuicio del alma del difunto y de sus herederos lo cual cumplan así dichos herederos bajo pena de excomunión y apercibimiento y manda que bajo las mismas penas y censuras dicho abad o cura lo haga obserbar sin condición alguna ${ }^{23}$. Para evitar toda ocasión de gastos de los mayordomos de las cofradías o fábrica, de las limosnas de las cofradías, de los fondos de estas o de sus casas lo que puede hacerles falta para la subsistencia de sus familiares, manda que dichos mayordomos con motivo de cofradías, indulgencias, jubileos o otras cualesquiera fiestas, funciones fúnebres no ponga rosca, ni hogazas, ni comidas para los eclesiásticos que asistan a ellas ni para otras personas algunas, ni dé refresco por la tarde a dichos eclesiásticos. Prohíbe que vayan a las dichas comidas y refrescos aunque voluntariamente sean convidados por los mayordomos a quienes únicamente les permite donde haya costumbre dar la moderada parva reducida a un cuarto de pan y a medio cuartillo de vino

\footnotetext{
${ }^{20}$ VIEITE, San Adrián. 22.19.9, fol. 17.

${ }^{21}$ VIEITE, San Adrián. 22.19.9, fol. 91v. VILLAR DE CONDES, Santa María. 22.19.7, fol. 54v.

${ }^{22}$ VIEITE, San Adrián. 22.19.9, fol. 12.

${ }^{23}$ VIEITE, San Adrián. 22.19.9, fol. 18.
}

"CUADERNOS DE ESTUDIOS GALLEGOS", Tomo XLVII, Fascículo 113, Santiago 2000. 
sin otra cosa ni aumento ${ }^{24}$. Manda S. Ilma. bajo pena de excomunión mayor y de 12 reales a los sacerdotes no asistan a los banquetes que suele haber en las fiestas y devociones de los santos por cuanto está informado S. Ilma. que se siguen de ello graves escándalos, ruidos y otras cosas muy indecentes y peligrosas así en lo espiritual como en lo temporal y a los dichos mayordomos no den dinero bajo las mismas censuras ${ }^{25}$. Por cuanto está informado S. Ilma. que las cofradías están pobres y sin la decencia debida por causa de las comidas que se hacen los días de los patronos manda S. Ilma. que bajo pena de excomunión mayor con apercibimiento que de aquí en adelante no haya tales comidas y que si algún mayordomo quisiere por su cuenta hacerlas que sea por su cuenta y los demás cofradas no le paguen cosa alguna y a los que esto contradijeren el abad les evite de los oficios divinos. Bajo las mismas penas manda que todos paguen los dos reales acostumbrados para que gocen de la cera y de los sufragios acostumbrados cuando se mueran ${ }^{26}$.

\section{9.- ASISTENCIA DE SACERDOTES A FIESTAS}

Teniendo presentes los muchos escándalos que se han cometido de concurrir los clérigos y sacerdotes a las fiestas con motivo de los patronos de las parroquias, santuarios y otras funciones y romerías, manda segunda vez bajo pena de 10 ducados que ninguno concurra a ellas, ni salga de sus casas con pretexto alguno por la tarde en la feligresía de la festividad y le encarga al abad que cuide de que esto se cumpla ${ }^{27}$. Por cuanto está informado de que algunos eclesiásticos de este partido con grande menosprecio del estado que profesan en cualesquiera festividades que haya concurren a los burcos y danzas que hacen los seglares mezclándose con ellos a danzar y a tocar, para que se atajen los inconvenientes que se pueden ocasionar y el menosprecio y la indecencia de su estado manda que los dichos, por ningún motivo ni pretexto concurran a dichos burcos no toquen ni dancen públicamente ni en secreto ni con otros por no ser de su

\footnotetext{
${ }^{24}$ REGODEIGÓN, San Cristobo. 37.6.8, sin foliar.

${ }^{25}$ VILLAR DE CONDES, Santa María. 22.19.7, fol. 14v.

${ }^{26}$ VILLAR DE CONDES, Santa María. 22.19.7, fol. 10v.

${ }^{27}$ VIEITE, San Adrián. 22.18.9, fol. 106v.
}

"CUADERNOS DE ESTUdIOS GALLEGOS", Tomo XLVII, Fascículo 113, Santiago 2000. 
profesión antes bien como tales eclesiásticos deben ser los primeros que por las muchas ofensas y disensiones que de hacerlo se han ocasionado y experimentado. Le manda que lo cumplan con apercibimiento de que hicieren pasar S. Ilma. a castigarlos ${ }^{28}$. Nos llega la noticia de que algunos sacerdotes contraviniendo lo mandado en las visitas de los señores obispos sus antecesores van a santuarios y romerías de lo que se siguen muchos inconvenientes, en atajo de ellos les ordena y les manda S. Ilma. nuevamente se abstengan de ir a las expresadas romerías y santuarios así de dentro del obispado como de fuera en los días y tiempos en que hubiere concurso de gente aunque sea con pretexto de cumplir algún voto para decir misa y en tal caso lo hará más bien en otro distinto día en que haya concurso de gentes y así lo cumplan inviolablemente en virtud de santa obediencia y con apercibimiento de lo más a que haya lugar ${ }^{29}$.

\section{0.- PAGA DE LOS CLÉRIGOS}

El visitador está informado de que en este obispado se ha introducido la costumbre de que cuando hay alguna festividad de cofradía, bautismos, casamientos, velaciones, entierros y demás funciones de difuntos, las personas que los tienen llevan al abad y cura carnero, rueda de vaca, pernil, gallinas y otras cosas con pretexto de que es para comer el abad y los clérigos que asisten. Declara que los párrocos no puedan pedir esto ni otra cosa que en aquel tiempo con el nombre de regalo o de presentes daban algunos feligreses en semejantes ocasiones. Desde hoy en adelante lo prohibimos por este nuestro mandato y advertimos que los dichos abades y curas no tienen derecho que les ampare para pedir semejantes regalos ni los feligreses obligación de darlos al menos que alguno solo por su gusto y voluntad quiera hacerlos y en esta conformidad y no en otra lo permitimos y así lo cumpla con dar sus derechos en dinero ${ }^{30}$. Perciban los eclesiásticos todos los estipendios legítimamente introducidos que por ley o costumbre legítimamente introducida se le suelen dar por la administra-

\footnotetext{
${ }^{28}$ VIEITE, San Adrián. 22.18.9, fol. 17v.

${ }^{29}$ VILLAR DE CONDES, Santa María. 22.19.7, fol. 34. REGODEIGÓN, San Cristobo. 37.6.8, sin foliar.

${ }^{30}$ VIEITE, San Adrián. 22.18.9, fol. 19v.
}

"CUADERNOS DE ESTUDIOS GALLEGOS", Tomo XLVII, Fascículo 113, Santiago 2000. 
ción de algunos sacramentos o sacramentales pero no de modo que se niegue o se dilate la administración como simoníaco y no aumente los estipendios bajo pena de restitución con las cosas y lo mismo manda que se observe acerca de los entierros sin dilatarlos por causa de los estipen$\operatorname{dios}^{31}$. Estas dádivas tuvieron principio según S. Ilma. de las comidas y de los convites que entonces solían hacerse los cuales ya fueron prohibidos y además sólo se tolerarán si los dan voluntariamente y de pura gracia los feligreses. Sólo así pueden recibirlos dichos regalos los párrocos sin que por eso pase a hacerse costumbre. Exorta al abad haga saber a los feligreses que no están obligados de justicia en las expresadas ocasiones a contribuirle con las especies y cosas referidas ${ }^{32}$. Halló el visitador que el abad había alterado la costumbre que había de llevar a siete reales por las misas cantadas de las cofradías que hay en su parroquia percibiendo por ellas a diez reales, por ello manda al dicho abad se arregle a las costumbres antiguas de dichos seis reales y restituya lo que ha llevado demás de ellos y de haberlo así hecho remita certificación a la cámara de $\mathrm{S}$. Ilma. y así mismo no altere la costumbre que hay de percibir por la misa cantada de difunto 10 reales con apercibimiento de proceder contra el que hiciere lo contrario a lo que haya lugar ${ }^{33}$. Mandamos a los abades que eviten todo motivo de ser tenidos por interesados y de que piensen sus feligreses que no procuran la salvación de sus almas sino la propia utilidad y que les domina la avaricia por lo cual desengañe tanto a sus feligreses diciéndoles que no tienen obligación de dar semejantes cosas y que sólo pueden dichos abades y curas recibirlas de los que por su gusto y voluntad quieran darlas ${ }^{34}$.

\section{1.- ENTRADA DE CLÉRIGOS EN TABERNAS}

Manda que ningún clérigo in sacris entre en taberna alguna por ningún pretexto aunque sea dueño de la taberna por ser de notable indecencia al estado eclesiástico y por seguirse muchos pleitos, y riñas de semejantes entradas y lo cumplan bajo pena de excomunión mayor y de 20 ducados

\footnotetext{
${ }^{31}$ A.H.D.O.F.P. REGODEIGÓN, San Cristobo. 37.6.8, sin foliar.

${ }^{32}$ A.H.D.O.F.P. REGODEIGÓN, San Cristobo. 37.6.8, sin foliar.

${ }^{33}$ A.H.D.O.F.P. VIEITE, San Adrián. 22.18.9, fol. 29v.

${ }^{34}$ A.H.D.O.F.P. VIEITE, San Adrián. 22.18.9, fol. 105v.
}

"CUADERNOS DE ESTUDIOS GALLEGOS", Tomo XLVII, Fascículo 113, Santiago 2000. 
de multa que con efecto se ejecutará en sus personas y bienes y el abad y cura nos dé aviso de los transgresores bajo las mismas penas y censuras ${ }^{35}$. Manda que ningún clérigo in sacris entre en tabernas ni haga banquetes en ellas por la grave indecencia que se causa a su estado como S. Ilma. lo tiene mandado en la visita del año de $1725 \mathrm{y}$ el abad cele si alguno de los de su feligresía lo ejecuta y nos dará cuenta para castigarlos rigurosamente si no cumplen con este mandato ${ }^{36}$. Manda que no entren en tabernas en público ni en secreto bajo pena de excomunión mayor late sentencie ipso facto incurrenda ${ }^{37}$.

\section{2.- ASISTENCIA DE SACERDOTES A LAS FIESTAS}

Manda que los clérigos no asistan a los burcos y danzas que hacen los seglares comiendo y bebiendo en las casas de estos ni a danzar con ellos por causa y motivo alguno ${ }^{38}$. Los eclesiásticos deben ser los primeros que eviten los festejos, danzas y burcos o bureos exortando a los seglares que también lo observen por las muchas ofensas y disensiones que de hacerse lo referido se han ocasionado y experimentado lo cual cumplan y si no lo hicieren S. Ilma. pasará a castigarles con todo rigor $^{39}$.

\section{3.- CONFERENCIAS MORALES}

Haga el abad que al menos una vez a la semana se junten los eclesiásticos de esta feligresía y estudiantes de menores y los que pretendieren ordenarse y estudiar moral, para la conferencia de moral. La cuestión de cada semana y el que la defienda la señalará el abad. Si alguno falta el

${ }^{35}$ A.H.D.O.F.P. CARBALLEDA, San Miguel. 22.5.8, fol. 66v. VIEITE, San Adrián. 22.18.9, fol. 19.

${ }^{36}$ A.H.D.O.F.P. VILLAR DE CONDES, Santa María. 22.19.7, fol. 30v. VIEITE, San Adrián. 22.18.9, fol. 28.

${ }^{37}$ A.H.D.O.F.P. REGODEIGÓN, San Cristobo. 37.6.8, fol. $2 \mathrm{v}$.

${ }^{38}$ A.H.D.O.F.P. REGODEIGÓN, San Cristobo. 37.6 .8 , fol. $2 \mathrm{v}$. VIEITE, San Adrián. 22.18.9, fol. 57.

${ }^{39}$ A.H.D.O.F.P. VILLAR DE CONDES, Santa María. 22.19.7, fol. 25.

"CUADERNOS DE ESTUdIOS GALLEGOS", Tomo XLVII, Fascículo 113, Santiago 2000. 
abad le reprenda la primera, segunda y tercera vez y pasado este tiempo si no se enmendare nos lo avisará para proceder contra el conforme viére$\operatorname{mos}^{40}$. Una y otra vez el visitador renueva lo que está prevenido sobre los párrocos y sacerdotes como es la puntual observancia a las conferencias morales y de sagradas ceremonias. A los referidos párrocos y sus tenientes les recuerda la particular obligación que tienen de hacer cumplir este mandato $^{41}$. El visitador manda que se observe lo prevenido en la «Bula Apostólicii Ministerrii» teniendo indefectiblemente en un día a la semana la conferencia alterando de moralidad y de sagradas ceremonias de la misa entre el abad, los clérigos y estudiantes de dicha parroquia sin excusa alguna bajo excomunión mayor late sentencie en que incurren cada vez que no asisten a dichas conferencias no teniendo enfermedad o ausencia necesaria ${ }^{42}$. Nos dará cuenta de los que han faltado a ellas especificando las multas que les hubiere impuesto y si las han satisfecho o no y manda que así lo cumpla el abad bajo pena de 4 ducados de multa ${ }^{43}$. Por cuanto los abades y curas no convocan a los sacerdotes, clérigos y estudiantes de sus feligresías como está mandado por la «Bula Apostolicii Ministerii» expedida por Inocencio XIII y confirmada por Benedicto XIII para tener un día a la semana sus conferencias morales como en dicha Bula se previene alegando algunos la escusa de haber en su feligresía pocos clérigos y estudiantes manda al abad que de aquí en adelante convoquen los abades a sus clérigos y estudiantes para tener conferencia alternando un día sobre un punto de moralidad y otro para el rezo y las rúbricas o sobre las sagradas ceremonias de la misa y si en la feligresía no hubiese más que un clérigo consignado con ese sólo las tengan y si alguno de los clérigos no cumple con este mandato el abad o cura lo multe en medio real por cada vez que faltare y que el abad remita la justificación de haber cumplido sus feligreses con el precepto pascual certificando también si los eclesiásticos de su parroquia concurren a tener conferencias y las veces que faltaren a ellas especificando las multas que hubiese impuesto y si las han pagado ${ }^{44}$. Manda la asistencia del párroco y de los sacerdotes a las conferencias

\footnotetext{
${ }^{40}$ A.H.D.O.F.P. VIEITE, San Adrián. 22.18.9, fol. 19, 19v. y 20.

${ }^{41}$ A.H.D.O.F.P. REGODEIGÓN, San Cristobo. 37.6.8, fol. 11v.

${ }^{42}$ A.H.D.O.F.P. REGODEIGÓN, San Cristobo. 37.6.8, fol. 2.

${ }^{43}$ A.H.D.O.F.P. VILLAR DE CONDES, Santa María. 22.19.7, fol. 32.

${ }^{44}$ A.H.D.O.F.P. VIEITE, San Adrián. 22.18.9, fol. 28v.
} 
morales de doctrina cristiana y ceremonias de la misa que deben tener al menos un día en cada semana con lo cual cumplirá el abad y sacerdotes de esta parroquia cuando en la parte que le toca con apercibimiento y bajo las penas que S. Ilma. se sirviere tomar en caso de contravención ${ }^{45}$.

\section{4.- INSTRUCCIÓN CRISTIANA}

Los párrocos y sus tenientes tienen la obligación particular de explicar el santo evangelio y la doctrina cristiana a sus feligreses en todos los domingos y días festivos no sólo de adviento y cuaresma sino también en todos los demás días festivos del año en que los feligreses están obligados a acudir a oír misa procurando con el mayor cuidado que estén bien instruidos en ella y en buenas costumbres ${ }^{46}$. Ordena y manda S. Ilma. que en lo sucesivo no haga publicaciones ni advertencias algunas en la iglesia y capillas de la feligresía sobre asuntos profanos aunque no sea de los pertenecientes al cumplimiento de obras pías y bien del alma, lo que observe y haga observar el abad o cura y sólo lo harán éstos de lo que conduce al régimen espiritual ${ }^{47}$.

\section{5.- CONFESIONES}

El abad y más confesores aprobados no confiesen a ninguna persona sino en la iglesia, sacristía o pórtico de ella, salvo en algunos casos de necesidad forzosos que importe a la salud espiritual ${ }^{48}$. Por cuanto se han experimentado graves desórdenes en algunos sacerdotes que sin tener licencia administran el sacramento de la penitencia. Manda S. Ilma. que el abad no consienta que sacerdote alguno confiese en esta feligresía sin que primero haya exhibido la licencia que tiene para ello $^{49}$. Manda en virtud

${ }^{45}$ A.H.D.O.F.P. REGODEIGÓN, San Cristobo. 37.6.8, sin foliar.

${ }^{46}$ A.H.D.O.F.P. REGODEIGÓN, San Cristobo. 37.6.8, sin foliar.

${ }^{47}$ A.H.D.O.F.P. REGODEIGÓN, San Cristobo. 37.6.8, fol. 12.

${ }^{48}$ A.H.D.O.F.P. CARBALLEDA, San Miguel. 22.5.8, fol. 73.

${ }^{49}$ A.H.D.O.F.P. VIEITE, San Andrián. 22.18.9, fol. 92v.

REGODEIGÓN, San Cristobo. 37.6.8, sin foliar.

"CUADERNOS DE ESTUdIOS GALLEGOS". Tomo XLVII, Fascículo 113, Santiago 2000. 
de santa obediencia a todos los confesores de esta feligresía que no ejerzan este santo ministerio con rejillas manuales o portátiles, ramos ni otra cosa semejante como tampoco fuera de las iglesias igualmente manda que no reciban nada aunque sea la cosa más mínima de sus penitentes ni con pretexto de limosna ni de estipendio de misa y con el mismo rigor prohíbe que salgan de su feligresía a confesar en santuarios, ermitas y capillas en aquellos días en que hay mucho concurso de gentes en ellas dado que los fieles que quieren ganar la indulgencia pueden confesarse en sus respectivas iglesias. Manda a los abades que no permitan que en el distrito de su parroquia contravengan lo aquí prevenido ni que en semejantes días salgan los confesores ${ }^{50}$.

\section{6.- USO DE ALTARES PORTÁTILES}

Se ha informado también S. Ilma. que en algunas capillas o ermitas del obispado se dice misa delante de la parte de fuera y en altar que para esto se pone para fuera con el pretexto de que son reducidas y que no pueden acomodarse dentro las gentes del concurso en las funciones y festividades sin que para ello se haya obtenido licencia de S. Ilma. ni conste que la tengan de los obispos sus antecesores, se prohíbe este abuso por los muchos inconvenientes que se originan. Mandamos que siempre que no se pueda celebrar el santo sacrificio de la misa dentro de las capillas que están habilitadas con aquella devoción y respeto que se debe por el bullicio e incomodidad de los concurrentes la función pase a tenerse en la iglesia parroquial. El abad o cura de dicha feligresía no permita que ningún eclesiástico regular o secular diga misa en altares portátiles en la iglesia, casas particulares y ni en otra cualquier parte del districto de esta feligresía bajo pena de excomunión mayor y si algún regular pretendiese decirla o supieren que la ha dicho nos dé parte para proceder contra él con todo rigor de derecho. No permita que ningún sacerdote sea regular o secular que no conozca diga misa en esta feligresía sin exhibir ante el abad y cura las licencias y testimoniales que tuviese de su prelado ${ }^{51}$.

\footnotetext{
${ }^{50}$ A.H.D.O.F.P. REGODEIGÓN, San Cristobo. 37.6.8, sin foliar.

${ }^{51}$ A.H.D.O.F.P. VIEITE, San Adrián. 22.18.9, fol. 19v, y 20.
} 


\section{7.- TRATO SACERDOTAL}

Deseando que la clase sacerdotal sea tratada con las consideraciones que merece su alta dignidad y no menos que los señores párrocos se guarden el respeto y obediencia que les corresponde por su importante cargo exhortamos a los párrocos que traten a los coadjutores y a los sacerdotes asignados a sus iglesias con todo decoro y dulzura mirándolos en todo como hermanos iguales a ellos en dignidad no ocupándolos en asuntos ni ordenándoles cosas que desdigan de su dignidad y que les exponen a menosprecio de los seglares y no menos ordenamos a todos los eclesiásticos que guarden obediencia y sumisión a los párrocos en cuanto al ejercicio de su función en la parroquia diciendo en los días de precepto misa en el lugar y hora que les designen para mayor comodidad del pueblo exhortándoles así mismo a que según la medida de sus fuerzas ayuden a los párrocos en la explicación de la doctrina cristiana y a los que tienen licencia de confesar que se sienten en el confesionario con frecuencia procurando todos su propia satisfacción y la de los fieles en el ejercicio de los santos ministerios sacerdotales ${ }^{52}$.

\section{8.- SUPLENTES Y ESCUSADORES DE PÁRROCOS}

Por cuanto ha tenido noticia de que algunos clérigos de este obispado suelen poner por escusadores en las funciones llevando dichos clérigos el emolumento correspondiente a dichas funciones sin asistir a ellas por ser derechuras personales manda que de aquí adelante el abad de dicha parroquia no admita a ningún acólito ni tonsurado como escusador de dichos clérigos y que sean sacerdotes los que asistan a las funciones siendo siempre preferidos en esto los sacerdotes de dicha parroquia a los de fuera ${ }^{53}$.

\footnotetext{
${ }^{52}$ A.H.D.O.F.P. VIEITE, San Adrián. 22.18.9, fol. 149v.

${ }^{53}$ A.H.D.O.F.P. REGODEIGÓN, San Cristobo. 37.6.8, fol. $2 \mathrm{v}$.
}

"CUADERNOS DE ESTUdios GALLEGOS", Tomo XLVII, Fascículo 113, Santiago 2000. 


\section{9.- CONFESIÓN Y COMUNIÓN DE CLÉRIGOS}

Manda que los ordenados in sacris confiesen y comulguen todas las semanas y los clérigos de menores y los tonsurados al menos dos veces al mes y que todos los años se remita certificación jurada a la secretaría de cámara $^{54}$.

\section{0.- REZO DEL SANTO ROSARIOY LECTURA ESPIRITUAL}

Los clérigos de menores, tonsurados y ordenados in sacris se junten y concurran todas las mañanas a la parroquia y en ella antes de la primera misa recen el rosario de María Santísima y después tengan un rato de lección espiritual. De cómo observan dicho cometido en este mandato dará cuenta el abad a la secretaría de cámara ${ }^{55}$. Manda que los sacerdotes asistan con el abad al rosario para que con su ejemplo vayan los legos a obra tan meritoria. S. Ilma. concedió 40 días de indulgencias a todas las personas que con devoción asistieren a él. Manda que el abad tenga especial cuidado en rezar por la tarde el rosario convocando a los sacerdotes de la feligresía para que asistan a esta devoción y que a su imitación lo ejecuten los seglares y parroquianos de ella y rezará a la hora que haya tiempo para que las personas que asistan a él puedan retirarse a sus casas con día, como también los domingos y festivos lo rezarán antes de la misa popular.

\section{1.- PROCESIONES}

Al tiempo de salir las procesiones de la iglesia asistan a ellas los clérigos y ordenados in sacris para que de esta manera se haga con más decencia y devoción ${ }^{56}$. Manda que asistan los sacerdotes a las procesiones que hubiere en la iglesia ${ }^{57}$.

\footnotetext{
${ }^{54}$ A.H.D.O.F.P. REGODEIGÓN, San Cristobo. 37.6.8, fol. 2v. VIEITE, San Adrián. 22.18.9, fol. 57v.

${ }^{55}$ A.H.D.O.F.P. VIEITE, San Adrián. 22.18 .9 , fol. $57 \mathrm{v}$.

${ }^{56}$ A.H.D.O.F.P. BEIRO, San Pedro. 22.4.9, fol. 58v.

${ }^{57}$ A.H.D.O.F.P. CARBALLEDA, San Miguel. 22.5.8, fol. 8.
}

"CUADERNOS DE ESTUdios GALLEGOS", Tomo XLVII, Fascículo 113, Santiago 2000. 


\section{2.- PRECEPTO PASCUAL}

Son pocos en número los feligreses que han dejado de cumplir con el precepto pascual, por las exortaciones que dirigí después de la visita del templo podrán los señores párrocos conocer mis deseos que continúen amonestándoles y que los reciban en cualquier tiempo con las debidas disposiciones y que entretanto no les admita por padrinos en los bautismos y si llegando el año que viene continuasen en su pertinacia no les bendigan sus casas a excepción de si fuese casado y el otro conyuge hubiese cumplido, ni los admita a la sepultura eclesiástica, si falleciesen sin haber dado muestra de arrepentimiento, además les excluirá de cualquier cofradía o hermandad a que perteneciesen ${ }^{58}$.

\section{3.- ORACIÓN POR LOS DIFUNTOS}

Por cuanto es cosa saludable hacer oración por las almas de los difuntos. Por las constituciones y sínodos de este obispado está mandado a todos los abades y curas que hagan tañer a las ánimas todas las noches. Manda que el dicho vicario tenga cuidado de que después de las oraciones se haga señal por las ánimas del purgatorio para que todos las encomienden a Dios y rueguen las libre de las penas que padecen y concedió a todas las personas que rezaren un padre nuestro y un ave maría por las ánimas de su padre, madre, hermano, pariente u otra persona de su obligación o por las que más necesidad tuvieren de sus oraciones en dichas penas 40 días de indulgencia y de perdón ${ }^{59}$.

\section{4.- NOMBRAMIENTO DE CONSILIARIOS}

Deseando que los caudales, haberes y efectos de la fábrica, cofradías y devociones de esa iglesia vayan en aumento y no en disminución ordena y manda que se nombre de dos en dos años tres consiliarios o mayordomos cuyas atribuciones serán las de proponer al párroco los mayordomos que

${ }^{58}$ A.H.D.O.F.P. VIEITE, San Adrián. 22.19.21, fol. 150.

${ }^{59}$ A.H.D.O.F.P. BEIRO, San Pedro. 22.4.9, fol. 42.

"CUADERNOS DE ESTUdIOS GALLEGOS", Tomo XLVII, Fascículo 113, Santiago 2000. 
hayan de elegirse cada año, asistir a la toma de cuentas que firmarán junto con el abad y los mayordomos entrante y saliente e intervenir con aquél en la inversión de dichos caudales ${ }^{60}$.

\section{5.- CAPILLA DE SANTA ELENA}

Habiendo visitado la capilla de Santa Elena sita en la feligresía de Vieite hallándose informado de los perniciosos desórdenes e irreverencias que se cometen en dicha capilla y a la santa cruz en el día de su festividad llevándose de ella vino y comidas que se gastan al pie de la expresada capilla y su monte con notable desenvoltura a fin de precaver estos inconvenientes y que la función se haga con la devoción y respeto que se requiere ordena y manda se cumpla lo mandado al respecto ${ }^{61}$.

\section{6.- LIMOSNAS PARA LA CAPILLA DE S. PEDRO TELMO Y PARA LA LÁMPARA DEL SANTÍSIMO}

Por cuanto es obligación precisa de todos los de este obispado que la capilla del glorioso San Pedro González Telmo nuestro patrono y de quien hemos recibido grandes beneficios sea asistida con el mayor culto y decencia que sea posible manda al abad ponga mucho cuidado y diligencia en que se coja limosna en esta iglesia por las casas después de cogidos los frutos la cual se remitirá a la ciudad de Tuy y se entregará al provisor de S. Ilma. quien dará de ella recibo cuando le remita la certificación de confesados $^{62}$. Manda al dicho abad tenga mucho cuidado de que se pida limosna para el glorioso mártir S. Pedro Telmo todos los domingos y fiestas de guardar al tiempo del ofertorio de la misa mayor como se dispone en las constituciones sinodales de este obispado y se remita a Tuy por la dominica de Quasimodo cada año junto con la matrícula de confesados ${ }^{63}$.

\footnotetext{
${ }^{60}$ A.H.D.O.F.P. REGODEIGÓN, San Cristobo. 37.6.8, sin foliar.

${ }^{61}$ A.H.D.O.F.P. VIEITE, San Adrián. 22.19.21, fol. 96.

${ }^{62}$ A.H.D.O.F.P. VILLAR DE CONDES, Santa María. 22.19.7, fol. 10v.

${ }^{63}$ A.H.D.O.F.P. BEIRO, San Pedro. 22.4.9, fol. 42.
}

"CUADERNOS DE ESTUdiOS GALLEGOS", Tomo XLVII, Fascículo 113, Santiago 2000. 
Los abades y curas de este obispado pidan por sí o por tercera persona la limosna para nuestro patrón San Telmo y para el culto y veneración de la capilla en que descansa su cuerpo y para las demás de la feligresía. No juzguen que lo recaudado se ha ejecutado mal lo cual es un error porque se gastó con mucha cuenta y razón en el culto y veneración del glorioso San Telmo y de su capilla. El abad tenga de aquí en adelante mucho cuidado en cumplir con esta obligación y lo que se gastare lo reduzca a dinero y lo remita a la penitenciaría de nuestra santa iglesia catedral y al arcipreste de este obispado para que lo remita cuando vaya por los óleos ${ }^{64}$. Por cuanto los vecinos de esta parroquia tienen devoción de dar cada año medio ferrado y uno de pan para que se compre cera para alumbrar al Santísimo Sacramento y para el día de su entierro y gastos de la iglesia manda que el despositario o mayordomo que recogiere esta limosna de ningún modo la emplee ni gaste ni compre cera alguna sin expresa licencia del $\mathrm{abad}^{65}$.

\footnotetext{
${ }^{64}$ A.H.D.O.F.P. VILLAR DE CONDES, Santa María. 22.19.7, fol. 20v.

${ }^{65}$ A.H.D.O.F.P. VILLAR DE CONDES, Santa María. 22.19.7, fol. 17.
}

"CUADERNOS DE ESTUDIOS GALLEGOS", Tomo XLVII, Fascículo 113, Santiago 2000. 